\title{
The use of combined treatments for reducing parabens in surface waters: Ion-exchange resin and nanofiltration
}

\author{
Carmen M. López-Ortiz ${ }^{\mathrm{a}, *}$, Irene Sentana-Gadea ${ }^{\mathrm{a}}$, Pedro Varó-Galvañ ${ }^{\mathrm{a}}$, Salvador E. Maestre-Pérez ${ }^{\mathrm{b}}$, \\ Daniel Prats-Rico ${ }^{\text {a }}$ \\ ${ }^{a}$ University Institute of Water and Environmental Sciences, University of Alicante, 03690, San Vicente del Raspeig, Alicante, Spain \\ b Analytical Chemistry, Nutrition and Food Science Department, University of Alicante, 03690, San Vicente del Raspeig, Alicante, Spain
}

\section{A R T I CLE IN F O}

Article history:

Received 16 March 2018

Received in revised form 12 May 2018

Accepted 12 May 2018

Available online $\mathrm{xxx}$

Editor: D. Barcelo

Keywords:

Magnetic resin

MIEX resin

Nanofiltration

Parabens

Water treatment

\begin{abstract}
A B S T R A C T
In this study, the removal of parabens from waters, using a combined treatment of magnetic ion exchange resins and subsequent filtration through nanofiltration membranes, was investigated. The selected parabens were methylparaben, ethylparaben, propylparaben and butylparaben. Two different magnetic anionic exchanger resins, MIEX ${ }^{\circledR}$ DOC and MIEX® GOLD, and two nanofiltration membranes (NF), NF-90 and DESAL-HL, were tested. The study was carried out using mono and multicomponent systems, using deionized water and natural waters sampled from two different rivers. In this way, competitive and matrix effects could be evaluated. The results showed, that with the combined treatments, higher elimination rates were obtained. The best removal efficiencies were obtained when the DOC resin was combined with both NF-90 and DESAL-HL membranes. Thus, butylparaben and propylparaben reached removal yields around $100 \%$ with both membranes, whereas the corresponding values for methylparaben were $91 \%$, when the NF-90 membrane was employed, or $92 \%$ when DESAL-HL membrane was utilized. The elimination rates of ethylparaben with the same treatments were $96 \%$ with the NF-90 and $97 \%$ when the DESAL-HL membrane was combined with the DOC resin. The elimination percentages were higher as the paraben alkyl chain length increased. In addition, no competitiveness or matrix effects were detected. When the MIEX ${ }^{\circledR}$ GOLD resin was used for pre-treatment, membrane fouling worsened which indicated that resin selection needs to be carefully considered to achieve the best results.
\end{abstract}

\section{Introduction}

Parabens are a family of compounds that are widely used in personal care products, as food preservatives or in the pharmaceutical industry. Common paraben group members include methyl, ethyl, propyl and butylparaben. Their widespread use has resulted in their detection in human fluid samples, e.g. in human blood, urine and breast milk, of different human populations and in environmental samples, such as waste water, treatment plant effluents and in rivers (Canosa et al., 2006; Li et al., 2016). Recent reports have indicated that exposure to parabens may modulate or disrupt the endocrine system and may, therefore, have harmful consequences on human health (Okubo et al., 2001; Soni et al., 2005). The presence of emerging contaminants in the aquatic environment is widely studied. The existence of parabens in continental waters is mainly attributed to discharges from waste water plants, with methylparaben and propylparaben being the most commonly detected due to their increased use in cosmetic products (Haman et al., 2015).

The concentration range of parabens detected is variable, for example, in surface water levels between 15 and $400 \mathrm{ng} / \mathrm{L}$ have been

\footnotetext{
* Corresponding author.

Email address: clo@ua.es (C.M. López-Ortiz)
}

detected for parabens, including the sum of Benzylparaben, Butylparaben, Ethylparaben, Isobutylparaben, Methylparaben and Isopropylparaben (Brausch and Rand, 2011). Yamamoto et al. (2011) found concentrations of $670 \mathrm{ng} / \mathrm{L}$ for methylparaben, 207 for $\mathrm{n}$-propylparaben and $163 \mathrm{ng} / \mathrm{L}$ for $\mathrm{n}$-butylparaben in a sewerage system, and they studied their toxicity to three aquatic organisms. Toxicity increases with increasing alkyl chain length (Brausch and Rand, 2011; Yamamoto et al., 2011). Gorga et al. (2015) detected methylparaben, ethylparaben and propylparaben in the Spanish rivers Ebro, Llobregat, Júcar and Guadalquivir in maximum concentrations of $142 \mathrm{ng} / \mathrm{L}$ (Ebro River), 49 ng/L (Jucar River), 26 ng/L (Guadalquivir River). Esteban et al. (2014) detected ethylparaben, propylparaben and triclosan at maximum concentrations of 16,38 , and $184 \mathrm{ng} / \mathrm{L}$, respectively, in the Jarama and Manzanares rivers.

As regards the removal of parabens, treatment with granular activated carbon was only effective in reducing benzylparaben, whereas treatment with $\mathrm{ClO}_{2}$ allowed removal of $>70 \%$ for methylparaben, propylparaben and benzylparaben (Gabarrón et al., 2016).

Since their introduction in the late 1950s, the use of membranes in water treatment processes has substantially increased. The development of new generation membranes and knowledge gained through research about their properties has contributed to improvements in their performance and effectiveness. There are different classifications of membranes, one of which refers to their pore size, with mi- 
Table 1

List of compounds studied and physicochemical properties. ${ }^{\text {a }}$ (Agarwala et al., 2016).

\begin{tabular}{llll}
\hline Compound & MW $(\mathrm{g} / \mathrm{mol})$ & Log Kow $^{\mathrm{a}}$ & $\mathrm{pKa}($ Scifinder Database $)$ \\
\hline Methylparaben & 152.149 & 1.96 & 8.40 \\
Ethylparaben & 166.176 & 2.47 & 8.34 \\
Propylparaben & 180.203 & 3.04 & 7.91 \\
Butylparaben & 194.23 & 3.57 & 8.47 \\
\hline
\end{tabular}

Table 2

Values of TOC, UV $(254 \mathrm{~nm})$, SUVA, $\mathrm{pH}$ and conductivity of the natural waters used as matrix.

\begin{tabular}{lll}
\hline Parameter & Verde River water & Segura River water \\
\hline TOC $(\mathrm{mg} / \mathrm{L})$ & 6.8 & 5.7 \\
UV $(254 \mathrm{~nm})$ & 0.097 & 0.116 \\
SUVA $(\mathrm{L} / \mathrm{mg} \mathrm{m})$ & 1.4 & 2.0 \\
$\mathrm{pH}$ & 8.4 & 7.47 \\
Conductivity $(\mu \mathrm{S} / \mathrm{cm})$ & 3150 & 2600 \\
\hline
\end{tabular}

Note: Total Organic Carbon (TOC); Specific ultraviolet Absorbance (SUVA).

Table 3

Properties of the membranes studied.

\begin{tabular}{lll}
\hline & NF-90 & DESAL-HL \\
\hline Manufacturer $_{\text {Material }^{\mathrm{a}}}$ & Dow Chemical & GE Osmonics \\
MWCO $(\mathrm{Da})^{\mathrm{a}}$ & Polyamide TF & Polyamide TF \\
$\mathrm{J}_{0}\left(\mathrm{~m}^{3} / \mathrm{m}^{2} \mathrm{~s}\right)^{\mathrm{b}}$ & 200 & $150-300$ \\
Contact angle $\left.^{\circ}\right)$ & $2.4410^{-6}$ & $6.4810^{-6}$ \\
Charge $(\mathrm{pH} 7)$ & $54^{\mathrm{c}}$ & $52^{\mathrm{d}}$ \\
\hline
\end{tabular}

${ }^{a}$ Information provided by the manufacturer.

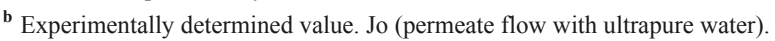

c (Boussu et al., 2006).

d (Hobbs et al., 2001).

e (Xu et al., 2006).

f (Braeken et al., 2006). MWCO (molecular weight cutoff).

crofiltration membranes, having the largest pore diameter, followed by ultrafiltration, nanofiltration (NF) and reverse osmosis membranes Due to their pore size NF membranes are used when low weight molecules need to be separated from the solvent. In addition, because of the membrane charge, water hardness can also be partially removed (Van Der Bruggen et al., 1998). During the last decade, NF membranes have been employed to remove the colour, produced by humic and fulvic acids, in surface and groundwater (Fu et al., 1994; Tan and Sudak, 1992) and also for the removal of trihalomethane precursors and organic microcontaminants (Lin et al., 2007; Phetrak et al., 2016; Uyak et al., 2008). In addition, the use of NF is particularly interesting in cases of chronic pesticide contamination (Tepuš et al., 2009), in the reduction of by-products of chlorination (Chalatip et al., 2009), and in the treatment of emerging organic contaminants such as en-

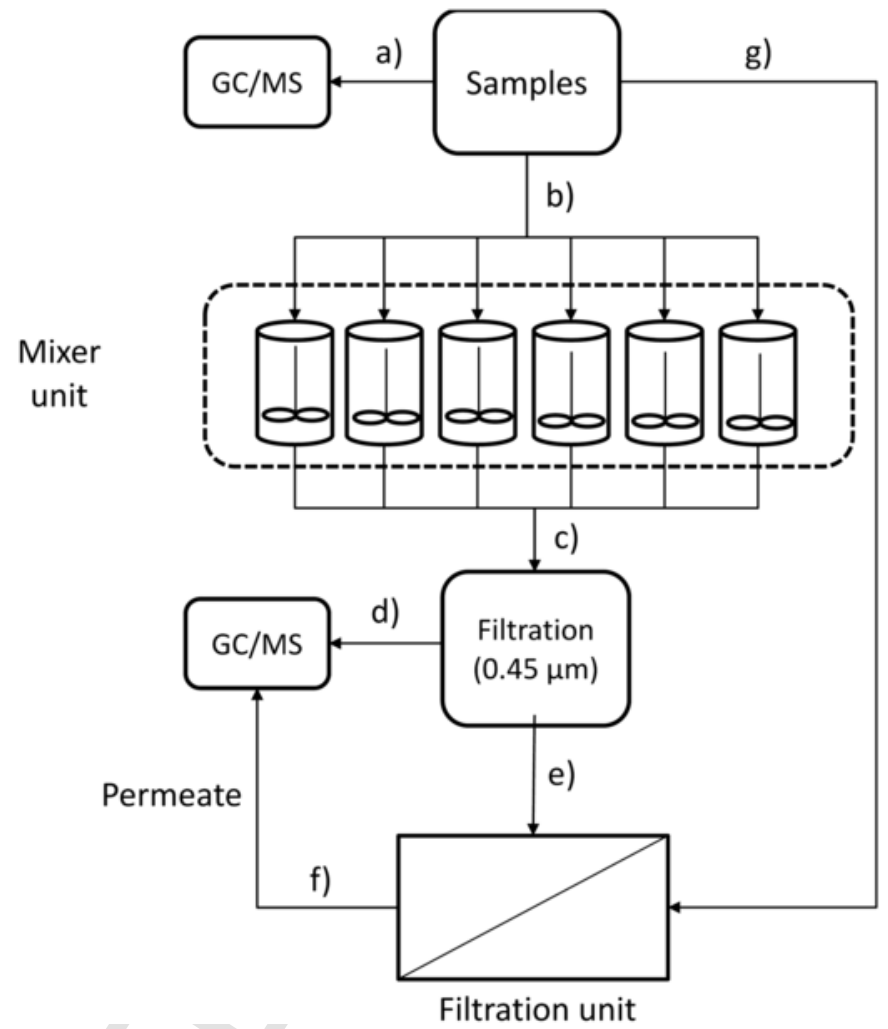

Fig. 1. Experimental design diagram summarizing how samples were treated; a) direct analysis, b) nanofiltration and b) and c) ion exchange plus nanofiltration.

docrine disruptors (Jin et al., 2010; Yüksel et al., 2013). For this last group of compounds different studies in which NF membranes have been employed to eliminate emerging contaminants, emphasize that removal efficiencies of contaminants are strongly affected by the physicochemical properties of the compounds (Kim et al., 2018; Bolong et al., 2009). NF has been effective in the elimination of some pharmaceutical products, obtaining percentages of reduction above $90 \%$ in some cases (Bolong et al., 2009) whereas for tor other structures, as Atrazine, percentages of removal were in the range of $20-85 \%$ depending on the selected NF membrane (Klüpfel and Frimmel, 2010). Yoon et al. (2006) studied the elimination of 27 endocrine disrupting compounds and pharmaceuticals by nanofiltration and ultrafiltration membranes without including any parabens in their study. They obtained better results when they used nanofiltration membranes than when they used ultrafiltration membranes, and also noted that compounds that were more polar, less volatile and less hydrophobic were eliminated worse, indicating that these removals could be governed by hydrophobic adsorption. Bolong et al. (2009) analyzed

Table 4

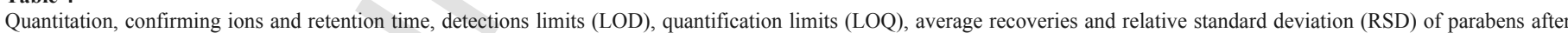
analysis by SPE followed by derivatization and GC-MS in the SIM mode.

\begin{tabular}{|c|c|c|c|c|}
\hline Parameter & Methyparaben & Ethylparaben & Propylparaben & Butylparaben \\
\hline Quantitation ion & 209 & 223 & 193 & 210 \\
\hline Confirming ions & 193,224 & 193,238 & 210,237 & 193,266 \\
\hline Retention time (min) & 6.41 & 6.93 & 7.74 & 8.75 \\
\hline $\begin{array}{l}\text { LOD } \\
\qquad(\mathrm{ng} / \mathrm{L})\end{array}$ & 2.6 & 2.7 & 2.5 & 1.8 \\
\hline $\begin{array}{l}\text { LOQ } \\
\quad(n g / L)\end{array}$ & 8.8 & 8.9 & 8.4 & 6.1 \\
\hline Average rexovery $(\%)$ & 86.8 & 67.9 & 75.2 & 63.7 \\
\hline RSD (\%) & 5.5 & 4.7 & 6.0 & 7.6 \\
\hline
\end{tabular}



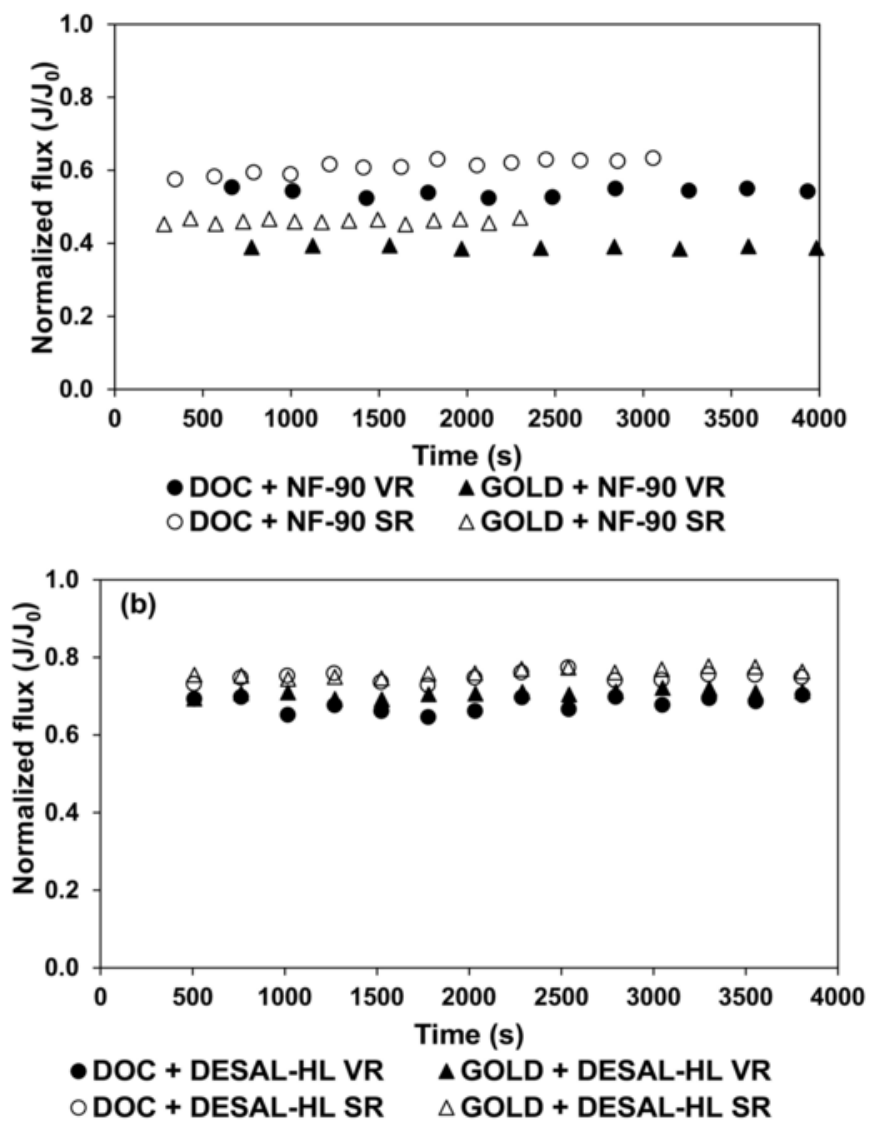

Fig. 2. Normalized flux profile versus time for each of the combined treatments was applied using the natural waters tested (Verde River (RV) and Segura (RS)) and membranes (a, NF-90 membrane; b, DESAL-HL membrane).

the use of activated carbon, oxidation, activated sludge, nanofiltration and reverse osmosis membranes, and their efficiency in the elimination of emerging contaminants present in wastewater, concluding that the mechanism of elimination of nanofiltration stands out for its great importance in the elimination of microcontaminants. Parabens were not included in this study among the pollutants studied.

However, the generalized use of NF membrane technology in the drinking water industry has been hampered by membrane fouling (Nghiem and Hawkes, 2009). Microorganisms, colloids, chemicals, and salts present in a feed solution can cause this problem. Fouling affects membrane performance by reducing solute retention. The extent and rate of membrane fouling are greatly affected by the surface characteristics of the membrane (Hong and Elimelech, 1997), the operating conditions and properties of the feed solution (Wang et al., 2008).

In recent years, studies on the use of pretreatment methods to minimize membrane fouling have been carried out; coagulation, activated carbon adsorption, advanced photooxidation, and ion exchange resin techniques have been investigated. The ion exchange processes prevent the formation of by-products and reduce the total organic carbon content of low and medium molecular weight compounds (Bourke et al., 2001). In addition, ion exchange resins can be regenerated whereas activated carbon and coagulant agents usually cannot, so this makes the use of ion exchange resins more cost effective.

There are a wide range of ion exchange resins available on the market. MIEX ${ }^{\circledR}$ resin (manufactured by Orica Chemicals) was developed in Australia in the mid-80s. Initially, its use was intended for the removal of organic matter (Aryal et al., 2015; Drikas et al., 2011), al- though its use also improves waters quality by removing inorganic ions such as nitrate, arsenate, bromide perchlorate and chromate (Hans et al., 2016; Tang et al., 2013). The use of MIEX ${ }^{\circledR}$ resin also improves the elimination of the by-products from disinfection processes such as halogenated derivatives derived from chlorine and bromine (Bond et al., 2010). Recent studies have shown that organic compounds with high toxicity such as drugs, hormones and personal care products can also be efficiently removed by using the MIEX ${ }^{\circledR}$ resin ( $\mathrm{Lu}$ et al., 2016). One type of substance usually found in personal care products is the group of compounds known as parabens.

As far as we know, there are no studies that address the removal of parabens from water samples with a combination treatment (i.e. ion exchange resins followed by nanofiltration). Thus, the objective of this study was to evaluate whether the combination treatment improved the removal yield of parabens when compared to the results achieved by each individual treatment. In addition, the influence of the chemical structure of the paraben on the removal efficiency will also be investigated. To carry out the study two ion exchange resins (MIEX ${ }^{\circledR}$ DOC and GOLD resin) were selected for the pretreatment stage. Two nanofiltration membranes (NF-90 and DESAL-HL membranes) were selected. The results in terms of removal efficiency and membrane fouling were evaluated using standard solutions and natural waters to which parabens had been previously added. There have not been any studies on the elimination of parabens with the resins and membranes used in this research to date.

\section{Materials and methods \\ 2.1. Reagents}

Solvents (ethyl acetate and methanol), pyridine, the derivatizing reagent $\mathrm{N}, \mathrm{O}$-Bis(trimethylsilyl) trifluoroacetamide (BSTFA) and 1\% trimethylchlorosilane (TMCS) and milli-Q water, of chromatography grade, were acquired from Sigma-Aldrich (Steinheim, Germany). Sulfuric acid $(96 \% \mathrm{w} / \mathrm{w})$ and pure pharma grade sodium bicarbonate, was purchased from Panreac (Barcelona, Spain).

Four compounds were studied (Table 1): methylparaben, ethylparaben, propylparaben and butylparaben. Carbamazepine-d10, was used as an internal standard. All these substances were purchased from Sigma-Aldrich (Steinheim, Germany) and were 98-99\% pure.

Oasis HLB $(6 \mathrm{~mL} / 60 \mathrm{mg})$ solid phase extraction cartridges used and were obtained from Waters (Milford, MA, USA).

\subsection{Standard solutions}

Stock solutions of parabens were prepared at $20,000 \mathrm{mg} / \mathrm{L}$ in methanol. From these stock solutions, intermediate diluted solutions of $2000 \mathrm{mg} / \mathrm{L}$ in methanol were derived. Working solutions of $50 \mathrm{mg} /$ $\mathrm{L}$ of each compound were obtained by the appropriate dilution of the intermediate solutions in methanol. All standard solutions were stored at $-20^{\circ} \mathrm{C}$ in amber glass bottles.

A stock solution of carbamazepine-d10 was prepared in methanol at $5000 \mathrm{mg} / \mathrm{L}$. The working internal standard solution, with a concentration of $500 \mu \mathrm{g} / \mathrm{L}$, was prepared from the stock solutions and stored at $-20^{\circ} \mathrm{C}$ in an amber glass bottle.

\subsection{Sample collection and preparation}

Deionized water and two natural water samples from the Verde and Segura rivers (both located in Alicante, Spain) were used as matrices for the experiments carried out in this study (Table 2). Original paraben concentrations were determined, using the methodology described in Section 2.6, in both natural water samples. Methylparaben and ethylparaben were found at concentrations below the limits of 

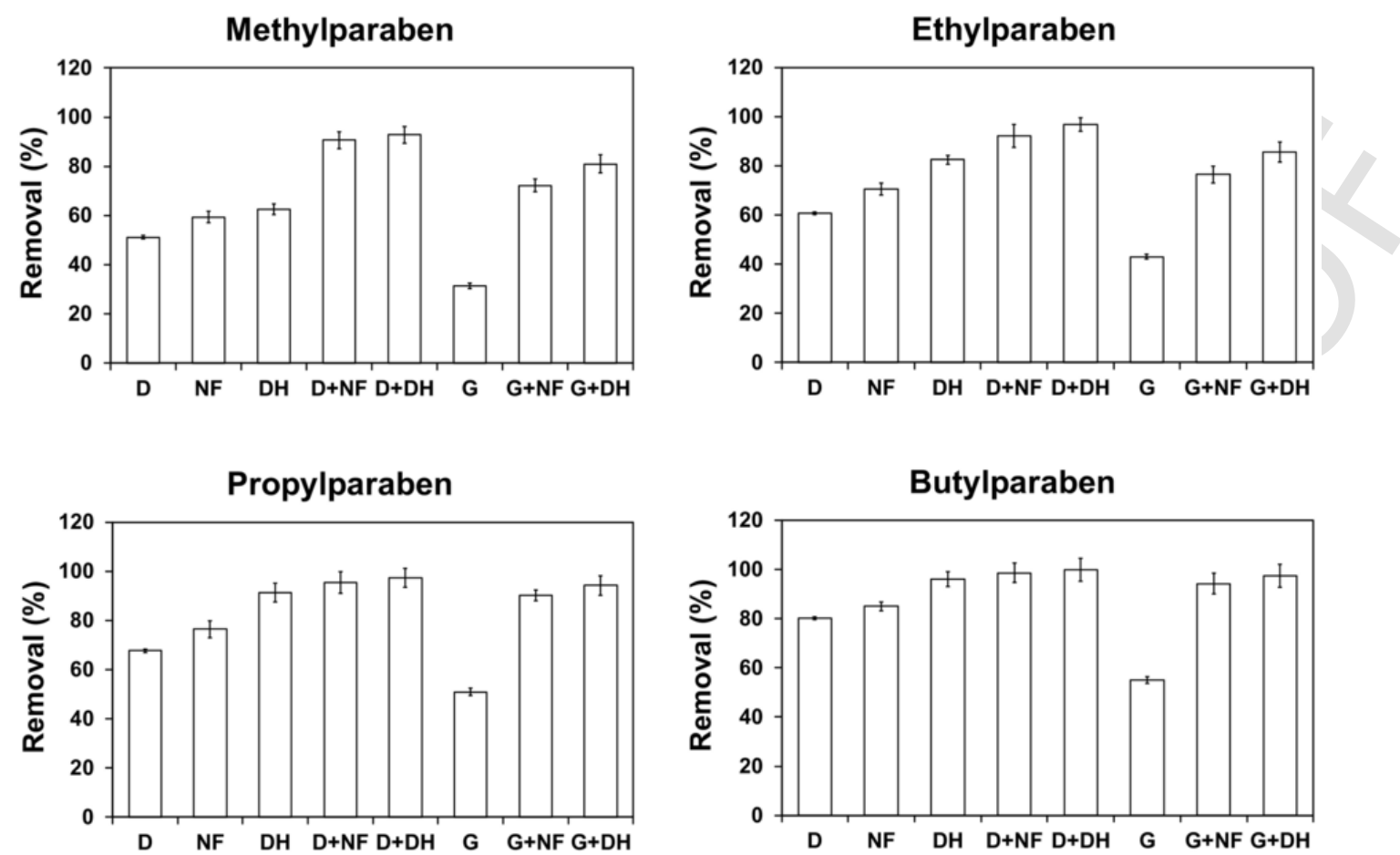

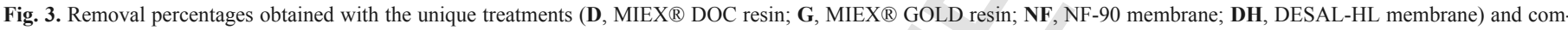

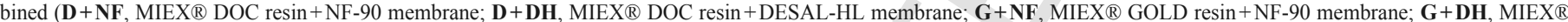

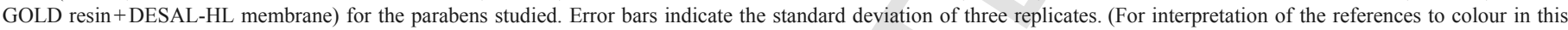
figure legend, the reader is referred to the web version of this article.)

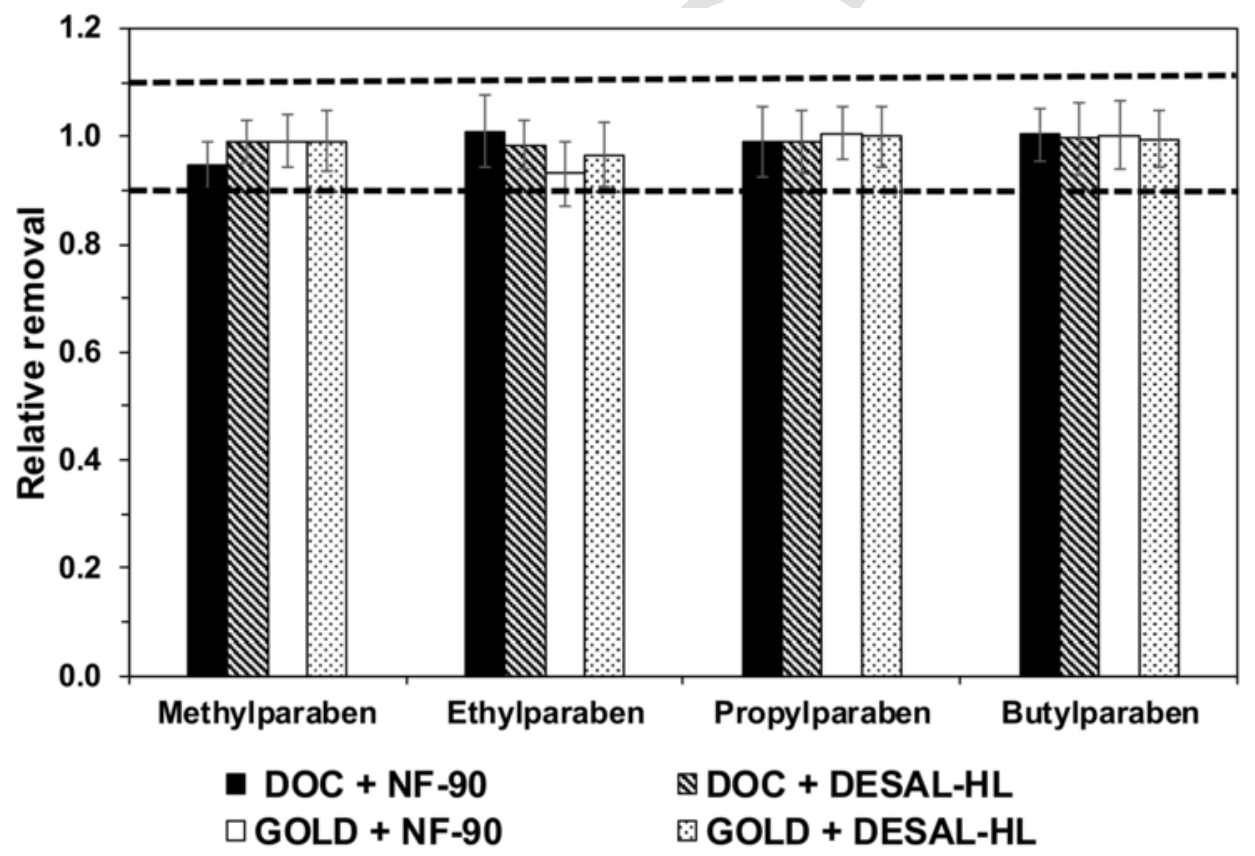

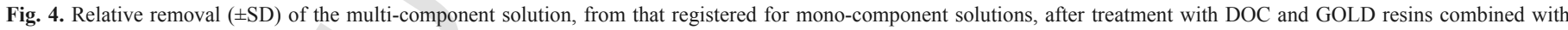
NF-90 and DESAL-HL membranes. (For interpretation of the references to colour in this figure legend, the reader is referred to the web version of this article.)

quantification in Segura River water whereas the levels in Verde River waters were 160 and $70 \mathrm{ng} / \mathrm{L}$ respectively. For propylparaben, the concentrations were 15 and $20 \mathrm{ng} / \mathrm{L}$ in Segura River and Verde River and values below quantification level. To evaluate the removal capacity of the selected contaminants by ion exchange and NF treat- ments, deionized water was employed with single component solutions at a concentration of $10 \mu \mathrm{g} / \mathrm{L}$ for each contaminant. This matrix was also used to evaluate the existence, or not, of competitive phenomena in the removal of these substances using $10 \mu \mathrm{g} / \mathrm{L}$ (of each substance) in multicomponent solutions. Afterwards, the natural wa- 


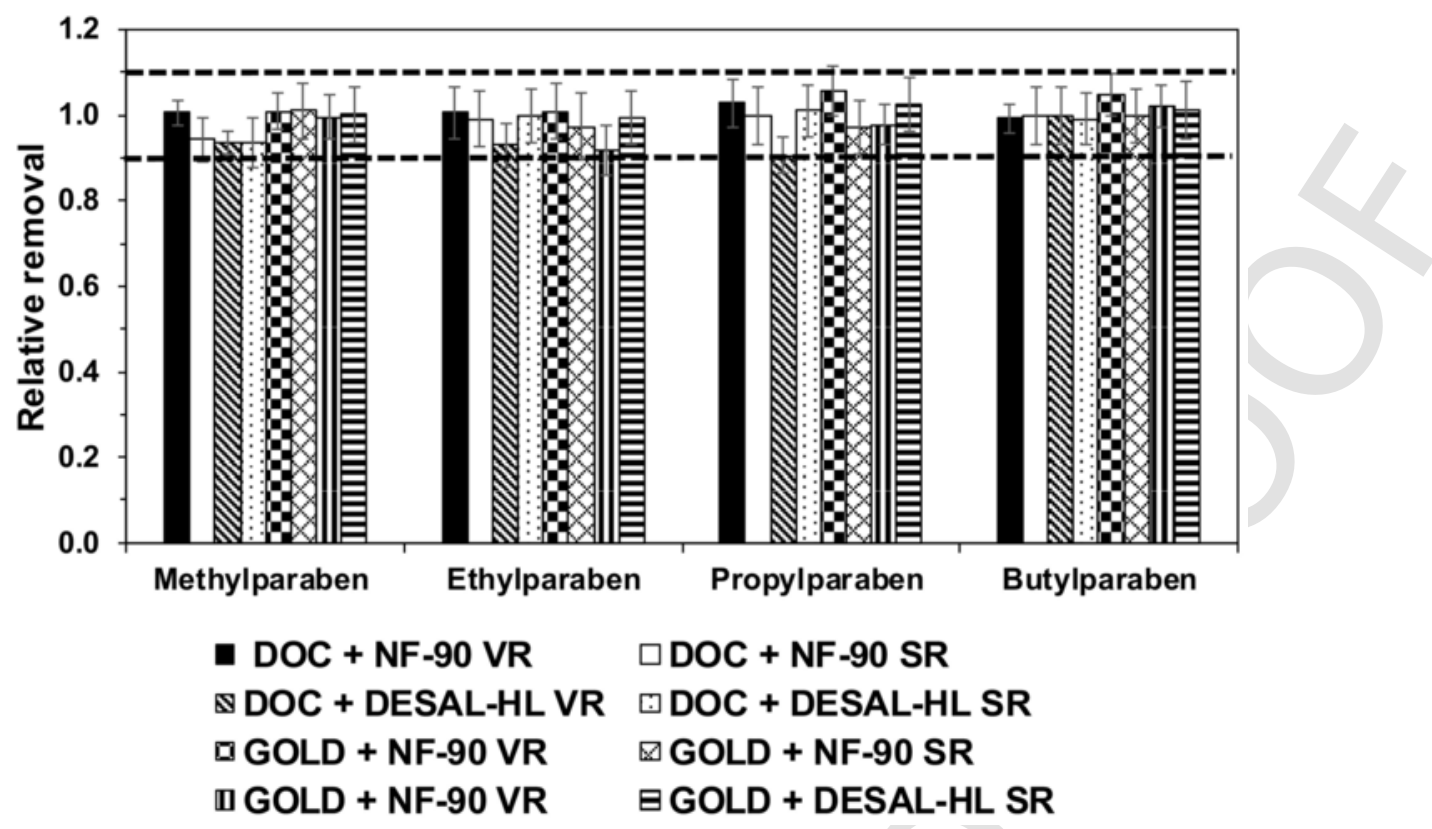

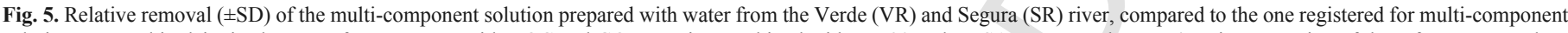

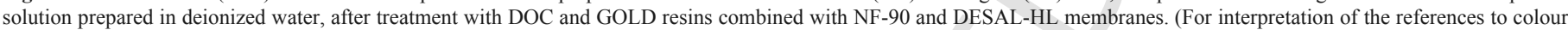
in this figure legend, the reader is referred to the web version of this article.)

ter samples were used to evaluate matrix influence in the adsorption and filtration processes using a multicomponent solution (again at $10 \mu \mathrm{g} / \mathrm{L}$ of each compound). These surface waters were collected in $40 \mathrm{~L}$ plastic containers that had been previously cleaned. The containers were rinsed three times with the sample waters before being eventually filled.

\subsection{Magnetic ion exchange and filtration membranes}

For the ion exchange tests, two strong base anion exchange resins were used. They contained a magnetic component, iron oxide, and this feature explains where the MIEX ${ }^{\circledR}$ product name comes from. The particle size of these resins is 2 to 5 times smaller than conventional resins, hence the capacity of exchange is higher, due to the increased external surface area. The two MIEX ${ }^{\circledR}$ resins studied were DOC and GOLD. The MIEX® ${ }^{\circledR}$ GOLD resin presents similar characteristics to the MIEX ${ }^{\circledR}$ DOC resin, however, it has a larger surface area, larger pores and a higher capacity to remove low molecular weight material than MIEX ${ }^{\circledR}$ DOC. Resins were supplied by IXOM Watercare Inc. in slurry form in $500 \mathrm{~mL}$ plastic containers. Before being used, both MIEX ${ }^{\circledR}$ resins were washed three times to remove impurities and were then stored in Millipore deionized water. The optimal resin dose used was $40 \mathrm{~mL} / \mathrm{L}$ and contact time $20 \mathrm{~min}$ for both resins.

Two nanofiltration membranes, NF-90 and DESAL-HL, were used for the filtration tests. Both membranes had a circular cross-section of $59.0 \mathrm{~mm}$ in diameter, with an effective surface area of $2734 \mathrm{~mm}^{2}$. General information about membranes, as well as some characteristics supplied by the manufacturers, is shown in Table 3 .

\subsection{Equipment and experimental approach}

A scheme of the experimental approach is depicted in Fig. 1. First a sample of the sample solution was taken and analyzed by GC-MS to establish the reference analyte concentration (step a). The rest of the solution was used to carry out the different treatments (steps b and g). First, a portion of the solution was used to study the paraben removal efficiency by using the MIEX ${ }^{\circledR}$ resins (step b). To this end, a 6-position digital flocculator was used for one litre of water, containing $10 \mu \mathrm{g} / \mathrm{L}$ of parabens, with $40 \mathrm{~mL} / \mathrm{L}$ of each resin, at a stirring speed of $250 \mathrm{rpm}$ for $20 \mathrm{~min}$ (the optimum dose of the resins and the contact time had been established in previous studies). The experiment was carried out at a room temperature of approximately $25 \pm 0.5^{\circ} \mathrm{C}$. The mixture was then settled for $10 \mathrm{~min}$. This solution was vacuum filtered through $0.45 \mu \mathrm{m}$ PVDF filters (Chmlab, Barcelona, Spain) to remove suspended particles (step c). Part of this solution was analyzed by GC-MS to evaluate the impact of resin usage (step d). With the remaining solution the combined resin and NF experiments were carried out using a NF unit with agitation (Amicon 8200, Millipore). This unit (step e) worked on loads $(200 \mathrm{~mL})$, with the flow direction perpendicular to the membrane surface, at a pressure of $300 \mathrm{kPa}$ (maintained by nitrogen) and at a constant stirring speed of $200 \mathrm{rpm}$, to minimize the effects of concentration by polarization. Once the NF experiments had ended, the permeate was analyzed by GC-MS (step f). With these results, the efficiency of the combined treatment was evaluated (resin + nanofiltration membrane). Finally, for comparison purposes the efficiency of the NF treatment was also measured by submitting the initial sample directly to the NF unit (step g) and analyzing the permeate by GC-MS. All experiments were repeated three times.

This scheme was followed using single component solutions as well as multicomponent solutions, to check the presence of competition among the parabens. The influence of the matrix was also evaluated by comparing the results for multicomponent solutions using deionized water and actual river water samples.

Before being analyzed, all samples were acidified with $96 \%$ sulfuric acid to $\mathrm{pH} \sim 3.0$ and the parabens were concentrated by means of a solid-phase extraction (SPE) procedure.

It should also be mentioned that the MIEX ${ }^{\circledR}$ resins were regenerated before each use using a solution of sodium bicarbonate $(12 \% \mathrm{w} /$ v). In addition, membranes were also renewed when the behavior for each compound had been studied. 


\subsection{Analytical method}

Automated SPE was performed using a Dionex Autotrace 280 (Thermo Scientific) instrument. A modification of the methods described by (Gómez et al. (2007) and Hai et al. (2011) was applied for the analysis of parabens. The cartridges used were pre-conditioned with $6 \mathrm{~mL}$ ethyl acetate, $6 \mathrm{~mL}$ methanol and $6 \mathrm{~mL}$ Milli-Q water. The samples $(500 \mathrm{~mL}$ each) containing the parabens were passed through the cartridges at a flow rate of $10 \mathrm{~mL} / \mathrm{min}$. The cartridges were then rinsed with $6 \mathrm{~mL}$ Milli-Q water and dried for $30 \mathrm{mins}$ by using a stream of nitrogen. Next, the parabens were eluted from the cartridges with $4 \mathrm{~mL}$ ethyl acetate followed by $4 \mathrm{~mL}$ ethyl acetate/ methanol $(1: 1, \mathrm{v} / \mathrm{v})$ at a flow rate of $4 \mathrm{~mL} / \mathrm{min}$. At this point, the internal standard $(100 \mu \mathrm{L}$ of methanol solution which contained $500 \mu \mathrm{g} /$ L carbamazepine-d10) was added to the eluates, and they were evaporated to dryness under a gentle stream of nitrogen in a heating block at $40^{\circ} \mathrm{C}$. Finally, the dry residues in the vials were derivatized by addition of $50 \mu \mathrm{L}$ of BSTFA:TMCS $(99: 1)$ and $50 \mu \mathrm{L}$ of pyridine, the derivatization was carried out at $60^{\circ} \mathrm{C}$ for $30 \mathrm{mins}$ in a heating block. The resulting solutions were cooled to room temperature and stored at $4{ }^{\circ} \mathrm{C}$ until required for analysis by $\mathrm{GC}-\mathrm{MS}$.

The analysis of the parabens was conducted using a gas chromatograph (Agilent $6890 \mathrm{~N}$ ) (interfaced with a quadrupole mass spectrometer (Agilent $5973 \mathrm{~N}$ ), equipped with a Gerstel cis $4+(\mathrm{PTV})$ autosampler). An Agilent 19091S-433 HP-5MS (5\% diphenyl-95\% dimethylpolysiloxane $)$ capillary column $(30 \mathrm{~m} \times 0.25 \mathrm{~mm} \quad$ ID, $\mathrm{df}=0.25 \mu \mathrm{m}$ ) was used. The flow rate of the carrier gas (helium) was maintained constant at $1.3 \mathrm{~mL} / \mathrm{min}$. The GC column temperature was programmed from $105^{\circ} \mathrm{C}$ (initial equilibrium time $1 \mathrm{~min}$ ) to $200^{\circ} \mathrm{C}$ via a ramp of $17^{\circ} \mathrm{C} / \mathrm{min}$ and maintained for $1 \mathrm{~min}$, then increased from 200 to $220^{\circ} \mathrm{C}$ using a ramp of $2^{\circ} \mathrm{C} / \mathrm{min}$ and maintained for 2 mins at $220^{\circ} \mathrm{C}$. The last step was to increase the temperature up to $290^{\circ} \mathrm{C}$ with a ramp of $5^{\circ} \mathrm{C} / \mathrm{min}$, this final temperature was maintained for $1 \mathrm{~min}$. The injector port and the interface temperature were maintained at 250 and $280^{\circ} \mathrm{C}$. Sample injection $(1 \mu \mathrm{L})$ was in splitless mode. For qualitative analysis, MS full-scan mode from $m / z, 50-600$ was used. Apart from the mass spectrum, the relative retention times of each compound were used for confirmation of the compound. Quantitative analysis was carried out using selected ion monitoring (SIM) mode. For each compound, the most abundant and characteristic ion was selected for quantification purposes (Table 4).

Calibration standards with concentrations in the $0.5-20 \mu \mathrm{g} / \mathrm{L}$ range were used. The raw analyte data was normalized by taking the ratio of the compound area to the internal standard area. For the calibration, linear function R-square values higher than 0.999 were always obtained. The limits of detection (LOD) and quantification (LOQ) were experimentally estimated as the lowest concentration level able to reach a signal-to-noise ratio of 3 for LOD and 10 for LOQ (Table 4).

Accuracy - expressed as percentage recovery- and precision -expressed in terms of relative standard deviation (RSD) - were evaluated by using single component standard solutions with a concentration of $10 \mu \mathrm{g} / \mathrm{L}$ for each paraben. The recovery and precision values obtained are the mean of six replicates from the analysis of the standards.

Conductivity, $\mathrm{pH}$, total organic carbon (TOC) and ultraviolet absorbance $\left(\mathrm{UVA}_{254}\right)$ of the Verde River water and Segura River water samples were determined from a $100 \mathrm{~mL}$ aliquot. The conductivity was measured using a CM 35 conductivity meter (Crison) and the $\mathrm{pH}$ by using a Basic $20+\mathrm{pH}$-meter (Crison). TOC was analyzed using a Shimadzu TOC-5000 analyzer, while ultraviolet absorbance was determined using a Shimadzu UV-1601 at a wavelength of $254 \mathrm{~nm}$. The reported values are the average of triplicate measurements, provided that the relative percent difference between triplicate samples and calibration check standards was $\leq 5 \%$.

\section{Results and discussion}

\subsection{Effectiveness of the pre-treatment on nanofiltration process}

Before discussing the effects of the combined treatments, it is important to note that when the NF process was the only treatment applied, the reduction in flow due to membrane fouling caused by the natural water composition was between $32 \%$ and $55 \%$ for the DESAL-HL and NF-90 membranes respectively when the Verde River water sample was used. The corresponding figures for the Segura River water sample were $25 \%$ and $46 \%$. As can be concluded, the DESAL-HL membrane showed less fouling tendency than the NF-90 one, irrespective of the water used, which could be attributed to its smaller average pore diameter. While the fouling was more severe when the Verde River water sample was filtered, it can be justified due to the differences in water composition. Hence, the Verde River water had conductivity and organic matter content roughly $20 \%$ higher than that of the NF Segura River water. The higher flow loss when the water from the Verde River was used can be explained by concentration polarization phenomenon, which reduces the permeability of the nanofiltration membrane. Other authors have obtained a decline in the flow rate when the conductivity of the water to be filtered increases (Jarusutthirak et al., 2007; Nanda et al., 2011). It is interesting to observe that a reduction in flow was noted at the beginning of each experiment. After nanofiltration of natural waters, membrane fouling was removed with a cleaning procedure using deionized water. A $100 \%$ recovery of the initial flow was registered for both membranes, which indicated that irreversible fouling was negligible.

When the MIEX resins were incorporated to develop the combined water treatment the observed scenarios were somehow dissimilar. Fig. 2 shows plots of the normalized flux profiles $\left(\mathrm{J} / \mathrm{J}_{\mathrm{o}}\right)$ versus NF time for each combined treatment using the sampled natural waters: Verde River (RV) and Segura River (RS). $\mathrm{J}_{0}$ is the permeate flow obtained when deionized water was filtered. In Fig. $2 \mathrm{a}$ the results achieved by the NF-90 membrane are shown while in Fig. $2 b$ data collected for the DESAL-HL membrane are plotted. Several conclusions can be drawn.

As in the single treatment, the flow reductions occurred at the beginning of the experiment, with the flow rates remaining almost constant throughout the entire test. The largest drop in flow occurred when the NF-90 membrane was used in combination with the two resins studied and for the two natural waters evaluated. For this membrane, Fig. 2a, when the Verde River water sample was treated with the MIEX ${ }^{\circledR}$ DOC resin and was filtered, an initial drop in the flow rate of $46 \%$ was seen. While the drop in flow was $39 \%$ when the water sample from the Segura River was filtered. This improvement in the flow rate is due to the reduction of dissolved organic matter present in the water since the MIEX ${ }^{\circledR}$ DOC resin has been designed to reduce the organic matter content in drinking water (Kitis et al., 2007; Nguyen et al., 2011). These results are in accordance with the values obtained by Imbrogno et al. (2018), where they indicate that pre-treatment with MIEX ${ }^{\circledR}$ DOC resin decreases the fouling of the NF90 membrane when they work at basic $\mathrm{pH}$.

When the water samples were treated with the MIEX ${ }^{\circledR}$ GOLD resin, the water from the Verde River caused a $61 \%$ drop in the flow and a 54\% drop when the water from the Segura River was filtered. These results indicated that an improvement in the NF process was found when the MIEX ${ }^{\circledR}$ DOC resin was used as a pre-treatment stage while the opposite conclusion could be drawn when the MIEX ${ }^{\circledR}$ GOLD resin was introduced. In this case, although MIEX ${ }^{\circledR}$ GOLD is 
also designed to reduce the organic matter content in water, the percentage of DOC reduction that it achieves is lower, especially when the water contains hydrophilic matter (Mołczan and Wolska, 2016). The waters used in this work have low SUVA values which are indicative of relatively low aromaticity and hence low hydrophobicity, which in turn could decrease the effectivity of the resin treatment. Another element that could explain the reduction of the nanofiltration flow is the resin settling properties. MIEX ${ }^{\circledR}$ GOLD resin showed worse settling properties than MIEX ${ }^{\circledR}$ DOC resin in the conditions of the experiments developed, hence, fractions of resin that may remain in solution could increase the fouling of the membrane. The MIEX ${ }^{\circledR}$ GOLD resin has a more positive zeta potential than that of the MIEX ${ }^{\circledR}$ DOC which enhances the attraction to the negatively charged surface of the NF membrane. Other studies about combination treatments use of Biological activated carbon followed by MIEX ${ }^{\circledR}$ DOC before nanofiltration, reduced fouling for nanofiltration membranes to $20 \%$ when they used polyvinyl alcohol/polyamide membranes with $700 \mathrm{Da}$ nominal molecular weight cut off (Aryal et al., 2015).

For the DESAL-HL membrane, Fig. 2b, when the MIEX ${ }^{\circledR}$ DOC resin was used, there was an initial drop of $32 \%$ in the flow rate for the Verde River water and $25 \%$ for the Segura River water. While the use of the MIEX ${ }^{\circledR}$ GOLD resin resulted in a $29 \%$ drop in the flow and a $24 \%$ fall for the Verde River and the Segura River waters. The incorporation of pre-treatment with MIEX ${ }^{\circledR}$ DOC resin did not reduce the fouling of the membrane with either of the two waters used. On the other hand, when treating the water with MIEX ${ }^{\circledR}$ GOLD resin, there was a certain reduction in fouling. The membrane has a lower negative surface charge and is slightly less hydrophobic than the NF-90 which may explain the results obtained.

When compared to the single NF treatment, the incorporation of the MIEX ${ }^{\circledR}$ resins can have a positive or a detrimental effect on the membrane fouling process, depending on the resin - membrane combination selected. The characteristics of the waters being treated also need to be considered, although in this study the variables which influenced the overall behaviour were not investigated. Finally, the reversibility of the fouling in the combined treatments was also confirmed in all experiments.

\subsection{Study of the removal of parabens}

Fig. 3 shows the results of the removal efficiencies of the parabens when the different water treatments were tested (i.e., single and combined treatments). These results were obtained using single compound solutions prepared in deionized water. For comparison purposes data of the removal efficiency attained by using only the MIEX resins is also included. It should be noted that with this treatment the lowest percentages of paraben removal were attained, with values of this parameter in the $31 \%$ to $80 \%$ range. The removal yields increased with the increased alkyl chain length of the paraben structures with the DOC resin being more effective for the removal of these substances than the GOLD one. Thus, for methylparaben, the use of the GOLD resin produced the poorest removal yield (i.e. $31 \%$ ) while the best result $(80 \%)$ was achieved for the butylparaben when the DOC resin was used.

When NF membranes were used as the only treatment method, paraben removal efficiencies increased, reaching values in the $60 \%$ to $96 \%$ range. Again, the best results were attained with the compounds that had longer alkyl chains. This concurs with the fact that the membrane surfaces have a certain hydrophobic character (see contact angle value in Table 3) therefore, for small substances, when the adsorption processes in the membrane surface control the removal yield, compounds with higher hydrophobicity are more easily removed than those with lower hydrophobicity. This conclusion has been made for other compounds (Nghiem et al., 2005; Yoon et al., 2004) and, according to the reported results, can also be applied to parabens (see values of log Kow in Table 1).

When the relative behaviour of the two membranes was compared it could be concluded that the DESAL-HL membrane always achieved higher removal efficiencies than the NF-90 membrane. This improved performance is related to the different molecular weight cut off values of the membranes (Table 3).

When the combined treatment (resin and membrane) was employed the overall observation was that the combined treatments achieved, for all compounds, better removal yields than single step treatments. The resins used are strong anionic exchangers thus, in such a context, the removal efficiency for non-ionized compounds, such as the members of the parabens family, was expected to be low. However, some researchers have investigated the mechanisms of removal of non-ionized compounds (Neale et al., 2010; Tang et al., 2014). Neale et al. (2010) argued that Van der Waals and hydrogen bonding with the polyacrylate polymer of the resin were the mechanisms responsible for the removal of the non-ionized compounds through the formation of hydrogen bonds with acceptor and donor groups present in the structure. This mechanism has also been proposed for the increase of removal capacity of antibiotics by MIEX resins (Wang et al., 2016).

The removal yield achieved depends on both the compounds evaluated and the combinations of resin and membrane selected. Thus, for long chain parabens (i.e., propyl- and butylparaben) as the removal efficiencies attained using membranes were already higher than $75 \%$, the inclusion of a pre-treatment with resins produced removal yields of $100 \%$ irrespective of the membrane used. In contrast, for parabens with shorter alkyl chains, despite the large improvement in the removal yields recorded with combined treatments, the values attained were in the $72 \%$ to $92 \%$ range for methylparaben and in the $76 \%$ to $97 \%$ range for ethylparaben, that is to say, values lower than $100 \%$.

When the resin and membrane combinations were evaluated, the combination of the DOC resin and the DESAL-HL membrane achieved improvements in the removal of methylparaben $(48 \%$ increase) and ethylparaben ( $17 \%$ increase). For the other two compounds, the changes recorded in the removal yields were not statistically significant. The results of the DOC and NF90 combination were similar, and although better improvements were found for propylparaben and butylparaben than when using a DESAL-HL membrane, their removal efficiency values were slightly lower.

For the GOLD resin, its combined use with the NF-90 membrane was less effective for paraben removal with improvements in the $8 \%$ to $22 \%$ range when compared to the values obtained with the treatment using only the membrane. From a statistical point of view only methylparaben and propylparaben presented significant differences with respect to the results obtained with the membrane (improvements of $22 \%$ and $18 \%$, respectively). Likewise, the combined treatment using the GOLD resin with the DESAL-HL membrane did not provide, in general terms, improvements compared with the single treatment using just the membrane. Methylparaben proved to be an exception for which removal efficiency increased by $20 \%$.

To summarize, the combined treatment with MIEX ${ }^{\circledR}$ resins and the DESAL-HL nanofiltration membrane achieved the best removal efficiencies for all parabens, improving the results registered in the single treatments using just the membrane or the resin. This improvement was more noticeable for parabens with shorter alkyl chain lengths. 


\subsection{Competitive effects on the parabens removal efficiency}

Fig. 4 shows the comparison of the relative removal efficiencies obtained after the treatment of multi-component solutions, with respect to the removal percentages obtained for the mono-component solutions (i.e. relative removal value of 1 ).

The results showed a slight decrease, from $4 \%$ to $7 \%$, in the efficacy of the elimination for the combined treatments under study using multicomponent solutions when compared with those achieved for single-component solutions. This variation in the efficacy of the elimination is within the error recorded in this type of test (i.e., $10 \%$, the value indicated by dashed lines in Fig. 4). Therefore, it can be concluded that there are no competitive phenomena in the elimination of the parabens, under the conditions tested.

\subsection{Influence of matrix on the parabens removal efficiency}

Fig. 5 shows the relative removal (relative to that obtained with multi-component solutions prepared with deionized water) for multi-component solutions prepared with the water samples from the Verde and Segura rivers, for each of the evaluated resins- membrane combinations.

It can be concluded that the matrix of the natural waters used did not affect the capacity of the combined treatment for removing parabens from these waters, since the decrease in elimination efficiency of the compounds tested is in the 2 to $9 \%$ range, this range is within the typical error established in this type of test (as we have already indicated, 10\%, dashed lines in Fig. 5).

As we have seen, the combined use of MIEX technologies and nanofiltration membranes allows us to improve the treated water quality by reducing the levels of compounds considered of environmental concern (i.e.,emerging pollutants). Although the initial design of the resins is not specifically focused on the elimination of this type of substances, but rather on dissolved organic matter that has higher molecular sizes (Wang and Ni, 2013), if the samples to be treated have a low DOM content, the elimination of these contaminants can be significant, contributing to increasing the time needed for the membranes fouling, as well as acting synergistically with the membranes to reduce the presence of contaminants in the filtrate. However, the conditions under which the best results can be obtained must be carefully studied in each case.

\section{Conclusions}

Pre-treatment of natural waters with $\mathrm{MIEX}{ }^{\circledR}$ resins can mitigate the process of membrane fouling due to the natural organic matter. However, a careful selection of resin is needed in order to achieve the best results, otherwise, a detrimental effect, as seen for the NF membrane, could be observed.

The combination of MIEX ${ }^{\circledR}$ resins and NF membranes improved the removal efficiencies of the shorter alkyl chain length parabens (i.e. methylparaben and ethylparaben). For propylparaben and butylparaben, an improvement was only achieved when the NF-90 membrane was used. However, the best removal efficiencies were obtained by the combined use of DOC resin with the DESAL-HL membrane.

No competitive effects were observed among the paraben compounds during their removal process. This is an interesting conclusion as, because of their widespread use, parabens are often found as contaminants in natural waters. Finally, the presence of natural organic matter did not affect the removal efficiency of the parabens. This result has important practical implications since in the event of decreased water productivity, the quality, in term of parabens levels, is not affected.

\section{Acknowledgements}

The authors would like to thank the Spanish Ministry of Economy and Competitiveness for their financial support during this study (project CTM2013-46669-R). The authors also gratefully acknowledge IXOM Watercare Inc. (Melbourne, Australia) for providing the MIEX ${ }^{\circledR}$ resins.

\section{References}

Agarwala, R., Barrett, T., Beck, J., Benson, D.A., Bollin, C., Bolton, E., Bourexis, D., Brister, J.R., Bryant, S.H., Canese, K., Charowhas, C., Clark, K., Dicuccio, M., Dondoshansky, I., Federhen, S., Feolo, M., Funk, K., Geer, L.Y., Gorelenkov, V., Hoeppner, M., Holmes, B., Johnson, M., Khotomlianski, V., Kimchi, A., Kimelman, M., Kitts, P., Klimke, W., Krasnov, S., Kuznetsov, A., Landrum, M.J., Landsman, D., Lee, J.M., Lipman, D.J., Lu, Z., Madden, T.L., Madej, T., Marchler-Bauer, A., Karsch-Mizrachi, I., Murphy, T., Orris, R., Ostell, J., O'sullivan, C., Panchenko, A., Phan, L., Preuss, D., Pruitt, K.D., Rodarmer, K., Rubinstein, W., Sayers, E., Schneider, V., Schuler, G.D., Sherry, S.T., Sirotkin, K., Siyan, K., Slotta, D., Soboleva, A., Soussov, V., Starchenko, G., Tatusova, T.A., Todorov, K., Trawick, B.W., Vakatov, D., Wang, Y., Ward, M., Wilbur, W.J., Yaschenko, E., Zbicz, K., 2016. Database resources of the National Center for Biotechnology Information. Nucleic Acids Res. 44, D7-D19. https://doi.org/10.1093/nar/ gkv1290.

Aryal, A., Sathasivan, A., Heitz, A., Zheng, G., Nikraz, H., Ginige, M.P., 2015. Combined BAC and MIEX pre-treatment of secondary wastewater effluent to reduce fouling of nanofiltration membranes. Water Res. 70, 214-223. https://doi.org/10. 1016/j.watres.2014.12.003.

Bolong, N., Ismail, A.F., Salim, M.R., Matsuura, T., 2009. A review of the effects of emerging contaminants in wastewater and options for their removal. Desalination 238, 229-246. https://doi.org/10.1016/j.desal.2008.03.020.

Bond, T., Goslan, E.H., Parsons, S.A., Jefferson, B., 2010. Disinfection by-product formation of natural organic matter surrogates and treatment by coagulation, MIEX ${ }^{\circledR}$ and nanofiltration. Water Res. 44, 1645-1653. https://doi.org/10.1016/j.watres. 2009.11.018

Bourke, M., Harrison, S., Long, B., Lebeau, T., 2001. MIEX ${ }^{\circledR}$ resin pretreatment followed by microfiltration as an alternative to nanofiltration for DBP precursor removal. In: AWWA Membr. Technol. Conf. Proc.. pp. 1-10.

Boussu, K., Zhang, Y., Cocquyt, J., Van der Meeren, P., Volodin, A., Van Haesendonck, C., Martens, J.A., Van der Bruggen, B., 2006. Characterization of polymeric nanofiltration membranes for systematic analysis of membrane performance. J. Membr. Sci. 278, 418-427. https://doi.org/10.1016/j.memsci.2005.11.027.

Braeken, L., Bettens, B., Boussu, K., Van der Meeren, P., Cocquyt, J., Vermant, J., Van der Bruggen, B., 2006. Transport mechanisms of dissolved organic compounds in aqueous solution during nanofiltration. J. Membr. Sci. 279, 311-319. https://doi.org/10.1016/j.memsci.2005.12.024.

Brausch, J.M., Rand, G.M., 2011. A review of personal care products in the aquatic environment: environmental concentrations and toxicity. Chemosphere https://doi. org/10.1016/j.chemosphere.2010.11.018.

Canosa, P., Rodríguez, I., Rubí, E., Negreira, N., Cela, R., 2006. Formation of halogenated by-products of parabens in chlorinated water. Anal. Chim. Acta 575, 106-113. https://doi.org/10.1016/j.aca.2006.05.068.

Chalatip, R., Chawalit, R., Nopawan, R., 2009. Removal of haloacetic acids by nanofiltration. J. Environ. Sci. 21, 96-100. https://doi.org/10.1016/S10010742(09)60017-6.

Drikas, M., Dixon, M., Morran, J., 2011. Long term case study of MIEX pre-treatment in drinking water; understanding NOM removal. Water Res. 45, 1539-1548. https: //doi.org/10.1016/j.watres.2010.11.024.

Esteban, S., Gorga, M., Petrovic, M., González-Alonso, S., Barceló, D., Valcárcel, Y., 2014. Analysis and occurrence of endocrine-disrupting compounds and estrogenic activity in the surface waters of Central Spain. Sci. Total Environ. 466-467, 939-951. https://doi.org/10.1016/j.scitotenv.2013.07.101.

Fu, P., Ruiz, H., Thompson, K., Spangenberg, C., 1994. Selecting membranes for removing NOM and DBP precursors. J. Am. Water Works Assoc. 86, 55-72.

Gabarrón, S., Gernjak, W., Valero, F., Barceló, A., Petrovic, M., Rodríguez-Roda, I., 2016. Evaluation of emerging contaminants in a drinking water treatment plant using electrodialysis reversal technology. J. Hazard. Mater. 309, 192-201. https:// doi.org/10.1016/j.jhazmat.2016.02.015.

Gómez, M.J., Martínez Bueno, M.J., Lacorte, S., Fernández-Alba, A.R., Agüera, A., 2007. Pilot survey monitoring pharmaceuticals and related compounds in a sewage treatment plant located on the Mediterranean coast. Chemosphere 66, 993-1002. https://doi.org/10.1016/j.chemosphere.2006.07.051. 
Gorga, M., Insa, S., Petrovic, M., Barceló, D., 2015. Occurrence and spatial distribution of EDCs and related compounds in waters and sediments of Iberian rivers. Sci. Total Environ. 503-504, 69-86. https://doi.org/10.1016/j.scitotenv.2014.06. 037.

Hai, F.I., Tessmer, K., Nguyen, L.N., Kang, J., Price, W.E., Nghiem, L.D., 2011. Removal of micropollutants by membrane bioreactor under temperature variation. J. Membr. Sci. 383, 144-151. https://doi.org/10.1016/j.memsci.2011.08.047.

Haman, C., Dauchy, X., Rosin, C., Munoz, J.F., 2015. Occurrence, fate and behavior of parabens in aquatic environments: a review. Water Res. https://doi.org/10.1016 j.watres.2014.09.030

Hans, R., Senanayake, G., Dharmasiri, L.C.S., Mathes, J.A.P., Kim, D.J., 2016. A preliminary batch study of sorption kinetics of $\mathrm{Cr}(\mathrm{VI})$ ions from aqueous solutions by a magnetic ion exchange $\left(\mathrm{MIEX}^{\circledR}\right)$ resin and determination of film/pore diffusivity. Hydrometallurgy 164, 208-218. https://doi.org/10.1016/j.hydromet.2016.06. 007.

Hobbs, C., Hong, S., Taylor, J., 2001. Fouling behavior of reverse osmosis and nanofiltration membranes during bench- and full-scale filtration of a high organic surficial groundwater. In: Membr. Technol. Conf., Proc. pp. 197-220.

Hong, S., Elimelech, M., 1997. Chemical and physical aspects of natural organic matter (NOM) fouling of nanofiltration membranes. J. Membr. Sci. 132, 159-181. https://doi.org/10.1016/S0376-7388(97)00060-4.

Imbrogno, A., Tiraferri, A., Abbenante, S., Weyand, S., Schwaiger, R., Luxbacher, T., Schäfer, A.I., 2018. Organic fouling control through magnetic ion exchange-nanofiltration (MIEX-NF) in water treatment. J. Membr. Sci. 549, 474-485. https://doi.org/10.1016/j.memsci.2017.12.041.

Jarusutthirak, C., Mattaraj, S., Jiraratananon, R., 2007. Factors affecting nanofiltration performances in natural organic matter rejection and flux decline. Sep. Purif. Technol. 58, 68-75. https://doi.org/10.1016/j.seppur.2007.07.010

Jin, X., Hu, J., Ong, S.L., 2010. Removal of natural hormone estrone from secondary effluents using nanofiltration and reverse osmosis. Water Res. 44, 638-648. https: //doi.org/10.1016/j.watres.2009.09.057.

Kim, S., Chu, K.H., Al-Hamadani, Y.A.J., Park, C.M., Jang, M., Kim, D.-H., Yu, M., Heo, J., Yoon, Y., 2018. Removal of contaminants of emerging concern by membranes in water and wastewater: a review. Chem. Eng. J. 335, 896-914. https://doi. org/10.1016/j.cej.2017.11.044.

Kitis, M., Ilker Harman, B., Yigit, N.O., Beyhan, M., Nguyen, H., Adams, B., 2007. The removal of natural organic matter from selected Turkish source waters using magnetic ion exchange resin (MIEX®). React. Funct. Polym. 67, 1495-1504. https://doi.org/10.1016/j.reactfunctpolym.2007.07.037.

Klüpfel, A.M., Frimmel, F.H., 2010. Nanofiltration of river water - fouling, cleaning and micropollutant rejection. Desalination 250, 1005-1007. https://doi.org/10. 1016/j.desal.2009.09.091.

Li, W., Gao, L., Shi, Y., Wang, Y., Liu, J., Cai, Y., 2016. Spatial distribution, temporal variation and risks of parabens and their chlorinated derivatives in urban surface water in Beijing, China. Sci. Total Environ. 539, 262-270. https://doi.org/10.1016/ j.scitotenv.2015.08.150

Lin, Y.L., Chiang, P.C., Chang, E.E., 2007. Removal of small trihalomethane precursors from aqueous solution by nanofiltration. J. Hazard. Mater. 146, 20-29. https:// doi.org/10.1016/j.jhazmat.2006.11.050.

Lu, X., Shao, Y., Gao, N., Chen, J., Zhang, Y., Wang, Q., Lu, Y., 2016. Adsorption and removal of clofibric acid and diclofenac from water with MIEX resin. Chemosphere 161, 400-411. https://doi.org/10.1016/j.chemosphere.2016.07.025.

Mołczan, M., Wolska, M., 2016. Removal Efficacy of Dissolved Organic Compounds with Low Specific Absorbance Value from Water by an Anion-Exchange Resin MIEX®Gold/Skuteczność usuwania rozpuszczonych związków organicznych z wody o małej wartości absorbancji właściwej na żywicy anionowy. Ochr. Środowiska. 38, 23-27.

Nanda, D., Tung, K.L., Li, Y.L., Lin, N.J., Lee, K.R., Chuang, C.J., Huang, S.H., 2011. Effects of ph and ionic strength on colloidal fouling of charged nanofiltration membranes. J. Chem. Eng. Jpn. 44, 476-485.

Neale, P.A., Mastrup, M., Borgmann, T., Schäfer, A.I., 2010. Sorption of micropollutant estrone to a water treatment ion exchange resin. J. Environ. Monit. 12, 311-317. https://doi.org/10.1039/B913338K.
Nghiem, L.D., Hawkes, S., 2009. Effects of membrane fouling on the nanofiltration of trace organic contaminants. Desalination 236, 273-281. https://doi.org/10.1016/j. desal.2007.10.077.

Nghiem, L.D., Schäfer, A.I., Elimelech, M., 2005. Nanofiltration of hormone mimicking trace organic contaminants. Sep. Sci. Technol. 40, 2633-2649. https://doi.org/ 10.1080/01496390500283340.

Nguyen, T.V., Zhang, R., Vigneswaran, S., Ngo, H.H., Kandasamy, J., Mathes, P., 2011. Removal of organic matter from effluents by magnetic ion exchange (MIEX®). Desalination 276, 96-102. https://doi.org/10.1016/j.desal.2011.03.028.

Okubo, T., Yokoyama, Y., Kano, K., Kano, I., 2001. ER-dependent estrogenic activity of parabens assessed by proliferation of human breast cancer MCF-7 cells and expression of ER $\alpha$ and PR. Food Chem. Toxicol. 39, 1225-1232. https://doi.org/10. 1016/S0278-6915(01)00073-4.

Phetrak, A., Lohwacharin, J., Takizawa, S., 2016. Analysis of trihalomethane precursor removal from sub-tropical reservoir waters by a magnetic ion exchange resin using a combined method of chloride concentration variation and surrogate organic molecules. Sci. Total Environ. 539, 165-174. https://doi.org/10.1016/j.scitotenv.2015. 08.111 .

Soni, M.G., Carabin, I.G., Burdock, G.A., 2005. Safety assessment of esters of p-hydroxybenzoic acid (parabens). Food Chem. Toxicol. https://doi.org/10.1016/j.fet. 2005.01.020.

Tan, L., Sudak, R.G., 1992. Removing color from a groundwater source. J. Am. Water Works Assoc. 84, 79-87.

Tang, Y., Liang, S., Guo, H., You, H., Gao, N., Yu, S., 2013. Adsorptive characteristics of perchlorate from aqueous solutions by MIEX resin. Colloids Surf. A Physicochem. Eng. Asp. 417, 26-31. https://doi.org/10.1016/j.colsurfa.2012.10. 040 .

Tang, Y., Li, S., Zhang, Y., Yu, S., Martikka, M., 2014. Sorption of tetrabromobisphenol a from solution onto MIEX resin: batch and column test. J. Taiwan Inst. Chem. Eng. 45, 2411-2417. https://doi.org/10.1016/j.jtice.2014.04.008.

Tepuš, B., Simonič, M., Petrinić, I., 2009. Comparison between nitrate and pesticide removal from ground water using adsorbents and NF and RO membranes. J. Hazard. Mater. 170, 1210-1217. https://doi.org/10.1016/j.jhazmat.2009.05.105.

Uyak, V., Koyuncu, I., Oktem, I., Cakmakci, M., Toroz, I., 2008. Removal of trihalomethanes from drinking water by nanofiltration membranes. J. Hazard. Mater. 152, 789-794. https://doi.org/10.1016/j.jhazmat.2007.07.082.

Van Der Bruggen, B., Schaep, J., Maes, W., Wilms, D., Vandecasteele, C., 1998. Nanofiltration as a treatment method for the removal of pesticides from ground waters. Desalination 117, 139-147. https://doi.org/10.1016/S0011-9164(98)000812 .

Wang, J.B., Ni, M.L., 2013. A critical analysis of MIEX application in water treatment. Adv. Mater. Res. 777, 86-91. https://doi.org/10.4028/www.scientific.net/ AMR.777.86.

Wang, L.K., Chen, J.P., Hung, Y.-T., Shammas, N.K., 2008. Membrane and Desalination Technologies. Springer.

Wang, T., Pan, X., Ben, W., Wang, J., Hou, P., Qiang, Z., 2016. Adsorptive removal of antibiotics from water using magnetic ion exchange resin. J. Environ. Sci. 52, 111-117. https://doi.org/10.1016/j.jes.2016.03.017.

Xu, P., Drewes, J.E., Kim, T.U., Bellona, C., Amy, G., 2006. Effect of membrane fouling on transport of organic contaminants in NF/RO membrane applications. J. Membr. Sci. 279, 165-175. https://doi.org/10.1016/j.memsci.2005.12.001.

Yamamoto, H., Tamura, I., Hirata, Y., Kato, J., Kagota, K., Katsuki, S., Yamamoto, A., Kagami, Y., Tatarazako, N., 2011. Aquatic toxicity and ecological risk assessment of seven parabens: individual and additive approach. Sci. Total Environ. 410-411, 102-111. https://doi.org/10.1016/j.scitotenv.2011.09.040.

Yoon, Y., Westerhoff, P., Yoon, J., Snyder, S.a., 2004. Removal of $17 \beta$ estradiol and Fluoranthene by Nanofiltration and ultrafiltration. J. Environ. Eng. 130, 1460-1467. https://doi.org/10.1061/(ASCE)0733-9372(2004)130:12(1460).

Yoon, Y., Westerhoff, P., Snyder, S.A., Wert, E.C., 2006. Nanofiltration and ultrafiltration of endocrine disrupting compounds, pharmaceuticals and personal care products. J. Membr. Sci. 270, 88-100. https://doi.org/10.1016/j.memsci.2005.06. 045

Yüksel, S., Kabay, N., Yüksel, M., 2013. Removal of bisphenol a (BPA) from water by various nanofiltration (NF) and reverse osmosis (RO) membranes. J. Hazard. Mater. 263, 307-310. https://doi.org/10.1016/j.jhazmat.2013.05.020. 